\title{
Effects of Micro-Textured Polystyrene Substrates by Compression Molding on Cell Adhesion and Proliferation
}

\author{
DENISE BELLISARIO ${ }^{1 *}$, FABRIZIO QUADRINI ${ }^{1}$, GUSTAVO SANTOLIM ${ }^{1}$, GIOVANNI MATTEO TEDDE ${ }^{1}$, VALERIO CAPUTO ${ }^{2}$, \\ PAOLA SPITALIERI ${ }^{2}$, FEDERICA SANGIUOLO2 ${ }^{2}$, LOREDANA SANTO ${ }^{1}$ \\ ${ }^{1}$ University of Rome Tor Vergata, Department of industrial Engineering, Via del Politecnico 1, 00133 Rome, Italy \\ 2 University of Rome Tor Vergata, Department of Biomedicine and Prevention, Via Montpellier 11, 00133 Rome, Italy
}

\begin{abstract}
Surface chemistry and micro-nanoscale topography of biomaterials can significantly influence tissue engineering and cell biology. In this study, polystyrene (PS) Petri dishes were subjected to microtexturing by compression molding process, which resulted in three-dimensional (3D) microscale surface topographies. Three different micropatterned surfaces were fabricated using bronze sintered molds with different mean pore pitch sizes. The surface changes and the morphological aspects were analyzed by 3D surface analyzer. The dishes were then used to investigate the cell behavior of Mouse Embryonic Fibroblasts (MEF) P4 cells. The surface micropatterning have affected in different ways the MEF cell adhesion and proliferation, related to the morphological changes in comparison with unmodified PS. At the increasing of the sintered particle dimensions of the mold, the cavities dimensions on the molded Petri increase and also the cells adhesion in the cavities seems to increase independently from the roughness inside them.
\end{abstract}

Keywords: micro-textured surfaces, compression molding, polystyrene substrate, cell adhesion and proliferation

Nowadays, thanks to technological innovations in surface engineering, many solutions have been found to change surface topography in micro and nano scale for mimicking natural hierarchical structures, mainly the lotus leaf [1]. Different technologies as chemical treatment or texturing have been developed for a lot of different application as biological usage, microfluidics, biomedical devices, hydrophobic or hydrophilic surfaces etc. [2-4]. In manufacturing, the research challenge is making hierarchical surfaces by mass-production technologies above all for polymers, elastomers [5] and thermoplastics [6]. Changes in the surface wettability as superhydrophobicity or superhydrophilicity can be obtained both by injection moulding of conventional polymers such as polypropylene [7] without affecting wear properties [8]. For example, polypropylene could be used for efficient selfcleaning and microfluidic manipulation [9].

The importance of surface hierarchy in medicine is deeply discussed in scientific literature but ithas been never evaluated for polymers. It is generally known that substrate surfaces and materials influence cell shape, adhesion, viability, motility, proliferation, function and differentiation $[10,11]$. Related effects can be inferred by extracting genes, and large differences in expression levels have been found [12]. Polymeric substrates can influence cultured human cells as well [13] but hierarchy has not been considered yet. At present, cell growth on hierarchical surfaces has been considered only for ceramic [14] and hybrid [15] substrates, mainly in bone tissue engineering [16]. At this point, it is evident the lack of scientific background about using organic substrates with hierarchical surfaces for biomedical purposes, even if polymers are optimal candidates for this application. Properties are given to the surface by means of its morphology. The goal is transferring to organic substrates the concepts which are already used in biomedicine in the case of non-organic substrates. In particular, biomedical research is constantly engaged in designing advanced cell culture systems using sophisticated micro-manufacturing technologies [17], beginning with the modification of polystyrene (biocompatible material) surfaces that have high transparency and low production and use costs [18]. In fact, commonly used substrates (in polystyrene or in general, all common plastic substrates for tissue culture) for cellular biology studies rarely reproduce in vitro the microenvironment in which the cells reside in vivo [19]: cells adhere to rigid and/or flat substrates resulting in biochemical and functional changes [20]. However, cells cultured in this way can be strongly influenced by the nature of the surface they adhere to [21]. In this context, the generation of micrometric and nanometric hierarchical surfaces is a way to mimic or modulate in-vivo threedimensional micro-environments. Thereby, cellular responses more similar to those within a tissue or organ can be induced remaining within the culture dishes.

For these reasons, the present study aims to evaluate the micro-texturing of commercial polystyrene Petri dishes surfaces which are commonly used in cellular biology studies as support for in vitro models. The authors in a previous study proposed a simple and low-cost fabrication method technique which permits the single-step production of multilevel three-dimensional surface structures of thermoplastic ABS thanks to compression molding of mechanically durable brass and bronze molds [22]. This method permitted also to modify the wetting properties of the molded substrates. In this study, the same technique is used for molding polystyrene substrates, which have to remain transparent after compression molding to allow microscopic observations. The micropatterned surface structures were characterized by a three-dimensional surface analyzer which facilitated a quantitative study of the peak distributions. Analysis showed that the microsculpturing technique in combination with compression molding is an appropriate tool for controlled production of surface patterning at a micro-nanometer scale preserving the transparency to allow microscopic observations for biological studies. Peak to valley distributions can be used for predicting surface structure-related properties for cell adhesion and proliferation. In fact, the micro-patterned Petri dishs were 
used as substrates to evaluate any changes in the adhesion and proliferation parameters of a type of cell frequently used in laboratory as mouse embryonic fibroblasts (MEF).

\section{Experimental part}

Materials and methods

Commercially available materials have been used for prototyping micropatterned surfaces. Sintered bronze filters (AMES S.A. Bronfil ® Filters) were used as microsculptured mold. The sintered bronze filters used are discs $(28 \mathrm{~mm}$ of diameter and $3 \mathrm{~mm}$ of thickness) made of particles of Bronze 89/11. The Petri dishes are Becton Dickinson Falcon ${ }^{8} 35 \mathrm{~mm}$ TC- Treated Easy-Grip Style Cell Culture Dishes. In particular, the Petri dishes are made of crystalgrade virgin polystyrene and have an internal diameter of $35 \mathrm{~mm}$ and a height of $10 \mathrm{~mm}$. They are commonly used for tissue cell culture and are treated by vacuum gas plasma to promote cell attachment. The sintered bronze discs used have different mean pore pitch sizes: $8 \mu \mathrm{m}$ (Sintered8), $24 \mu \mathrm{m}$ (Sintered24) and 60 $\mu \mathrm{m}$ (Sintered60).

A mold-holder has been designed and fabricated (figs. $1 a, b)$ in order to heat and hold the sintered bronze disc during the compression molding process phases. In particular, the micro-sculptured surfaces were fabricated using a very simple compression molding process: the sintered bronze disc was fixed into the mold-holder and heated on a hot plate until it reached a temperature of 170 ${ }^{\circ} \mathrm{C}$. Subsequently, the hot mold was positioned on the Petri dish for 3 min under a load of $150 \mathrm{~N}$ (figs. 1c,d and e). A thermocouple was used to check the mold temperature during heating and molding, while a loading cell was used to control the compression force during molding. The compression molding parameters used for the microtexturing operations are enough to reproduce the surface patterns of the mold and to partially preserve the transparency of the polystyrene substrate for microscopic observation of cells.

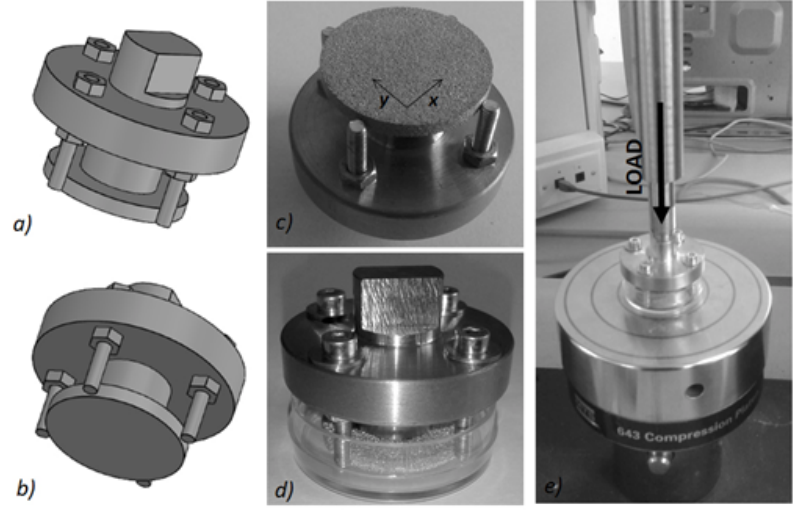

Fig. 1. CAD of the mold-holder device $(a, b)$; sintered bronze disc inserted into the mold-holder (c); mold positioning into the Petri dish (d) and compression molding step (e)

After molding the load was removed and the Petri sample left to cool at room temperature in contact with the mold. The same production process was used to generate all the three Petri dishes superficially molded with the three sintered bronze discs: Molded8, Molded24 and Molded60.

\section{Characterization}

The surface morphology of the three sintered bronze molds and of the Petri samples before and after microsculpturing by compression molding was investigated by Taylor Hobson Surface Topography System (TalySurf CLI 2000, Taylor Hobson, Leicester, UK), using the inductive gauge with a resolution range from $9.1 \mathrm{~nm}$ to $511 \mu \mathrm{m}$. For each sample, the surface morphology was analyzed by recording 1001 patterns, $1 \mathrm{~mm}$ spaced along the $x$ axis and $1 \mathrm{~mm}$ along the $y$ axis, so as to cover an area of 1 $\mathrm{mm}^{2}$. This area was measured in the central part of the Petri samples. TalyMap software Release 3.1 was used to get the surface parameters (cut off of $2.5 \mu \mathrm{m}$ and Gaussian filter of $0.25 \mu \mathrm{m}$ ) and, in particular, the average width and height of pattern profile in the $x$ and $y$ directions, the percentage distribution of the heights of the different areas and the roughness parameters before and after moulding process. After molding, the Petri dishes were used as biomedical support for evaluating the cell adhesion and proliferation. Mouse Embryonic Fibroblasts (MEF) P4 cells were seeded into the four sterilized Petri dishes: one as received (initial) as control sample and three with micropatterned surfaces. On each sample were inoculated $25000 \mathrm{MEF}$ cells and the adhesion was evaluated after $24 \mathrm{~h}$, while the cell proliferation was observed after $24 \mathrm{~h}$ and after 48h. The labelling of the nuclei (4,6-diamidino-2phenylindole (Dapi 1:1000)) was performed after $48 \mathrm{~h}$ to evaluate number of cells in relation to the cavities/ asperities of the micropatterned surface.

\section{Results and discussions}

Figure 2 shows the 3D maps of the three different molds (Sintered8, Sintered24, Sintered60) before compression molding operations, and two of their surface profiles along two different perpendicular directions ( $x, y)$. On each graph, the two profiles have been vertically shifted to optimize the comparison. After the 3D maps acquisition, the mean particle size of each sintered bronze filter was calculated, in particular Sintered60 consists of spherical particles of about $220 \mu \mathrm{m}$, Sintered 24 has spherical particles of about $80 \mu \mathrm{m}$ and Sintered8 has spherical particles of about 40 $\mu \mathrm{m}$.

As expected, the surfaces of the three molds differ from each other in the magnitude of the peak to valley mean value (Sintered 8 about $20 \mu \mathrm{m}$, Sintered 24 about $60 \mu \mathrm{m}$ and Sintered 60 about $100 \mu \mathrm{m}$ ) and of the mean peak
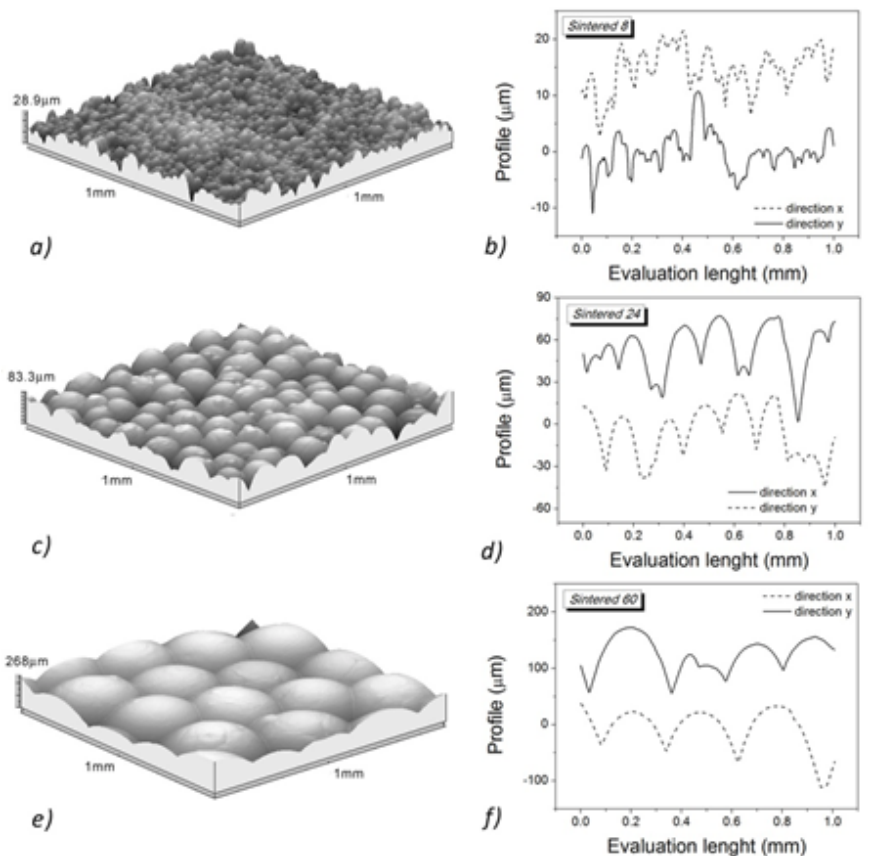

e)

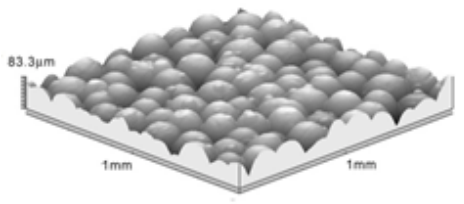

c)

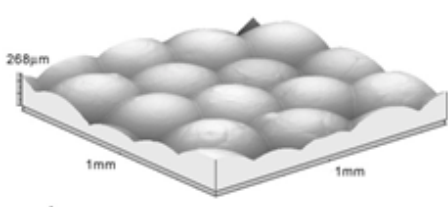

Evaluation lenght $(\mathrm{mm})$

Fig. 2. a) 3D map of the mold Sintered8 and b) two of its profiles in two different directions; c) 3D map of the mold Sintered24 and d)

two of its profiles in two different directions; e) 3D map of the

mold Sintered60 and f) two of its profiles in two different directions 


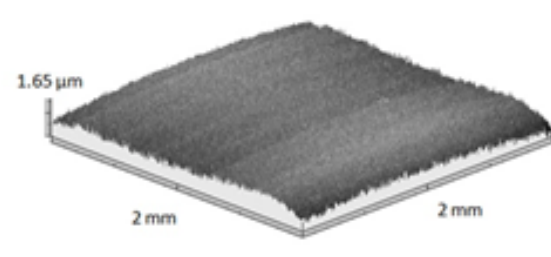

a)

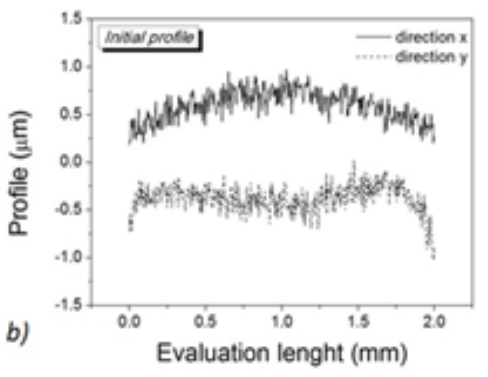

Fig. 3. a) 3D map of the initial surface of the Petri dish and b) two of its profiles in two different directions amplitude. However regardless of size, the peak to valley distribution of all the sintered bronze discs is very variable, and no preferable orientations are visible along the two directions in the $x-y$ plane. Anyhow, these geometrical differences in spacing and size of the peak-valley profiles of the molds were chosen to evaluate and to assess the ability of the compression molding process.

Figure 3 shows a 3D map of the initial surface of the Petri dish, and two of its profiles (vertically shifted) in two orthogonal directions. The initial surface roughness $R$ of the Petri substrate is around $0.05 \mu \mathrm{m}$ with low variability regardless of the direction of analysis (table1). Instead, there is a variability in the waviness measurements along the two orthogonal directions, the average waviness along $x$ is about $0.245 \mu \mathrm{m}$ while along y of about $0.082 \mu \mathrm{m}$. Such difference is even more evident by evaluating the total height of the profile waviness 1 im along $x$ and 0.64 along $y$. Consequently, the initial surface of commercial Petri dishes is not perfectly flat, independently from the surface micro-roughness. Probably this is due to the molding process with which commercial Petri dishes are manufactured.

Figure 4 shows the 3D maps of the molded surfaces for all the micropatterned samples, while figure 5 reports the Table1

ROUGHNESSPARAMETERS

\begin{tabular}{|c|c|c|c|c|c|c|c|c|c|c|c|c|}
\hline \multirow[b]{2}{*}{ Petri $\mathrm{x}$} & \multicolumn{2}{|c|}{$\mathrm{Ra}[\mu \mathrm{m}]$} & \multicolumn{2}{|c|}{ Rt $[\mu \mathrm{m}]$} & \multicolumn{2}{|c|}{$\mathrm{RSm}[\mathrm{mm}]$} & \multicolumn{2}{|c|}{$R \Delta q\left[^{\circ}\right]$} & \multicolumn{2}{|c|}{ Rsk } & \multicolumn{2}{|c|}{ Rku } \\
\hline & 0.051 & \pm 0.004 & 0.394 & \pm 0.042 & 0.028 & \pm 0.003 & 0.836 & \pm 0.107 & 0.017 & \pm 0.162 & 3.096 & \pm 2.426 \\
\hline Petriy & 0.050 & \pm 0.003 & 0.392 & $=0.040$ & 0.026 & \pm 0.002 & 0.877 & $=0.045$ & -0.013 & \pm 0.151 & 3.220 & $=0.331$ \\
\hline Molded8 x & 0.431 & \pm 0.099 & 3.084 & \pm 0.562 & 0.095 & \pm 0.020 & 3.033 & \pm 0.398 & -0.536 & \pm 0.557 & 3.533 & \pm 1.642 \\
\hline Molded8 y & 0.552 & \pm 0.111 & 3.274 & \pm 0.630 & 0.087 & \pm 0.017 & 3.939 & \pm 0.443 & -0.350 & \pm 0.338 & 2.946 & \pm 1.736 \\
\hline Molded $24 \mathrm{x}$ & 0.250 & \pm 0.149 & 3.241 & \pm 2.020 & 0.095 & \pm 0.048 & 2.731 & \pm 1.164 & -1.344 & \pm 2.229 & 10.417 & \pm 1.952 \\
\hline Molded $24 \mathrm{y}$ & 0.264 & \pm 0.118 & 3.189 & \pm 2.074 & 0.091 & \pm 0.037 & 3.212 & $=0.822$ & -1.395 & \pm 1.697 & 8.861 & \pm 2.108 \\
\hline Molded $60 \mathrm{x}$ & 3.061 & \pm 1.910 & 15.409 & \pm 5.139 & 0.231 & \pm 0.025 & 6.750 & \pm 3.646 & -0.406 & $=0.532$ & 3.914 & $=1.300$ \\
\hline Molded $60 \mathrm{y}$ & 2.281 & \pm 1.537 & 13.906 & $=4.668$ & 0.225 & \pm 0.032 & 6.693 & $=2.992$ & -0.750 & \pm 1.434 & 5.343 & $=1.364$ \\
\hline
\end{tabular}

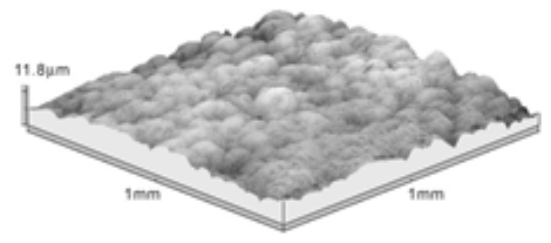

a)

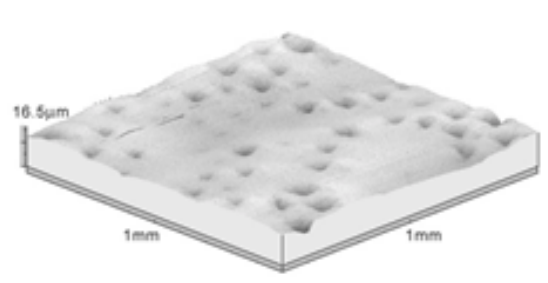

d)

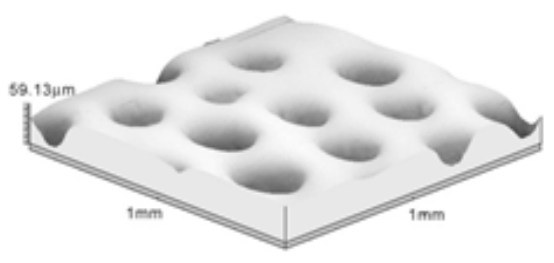

g)

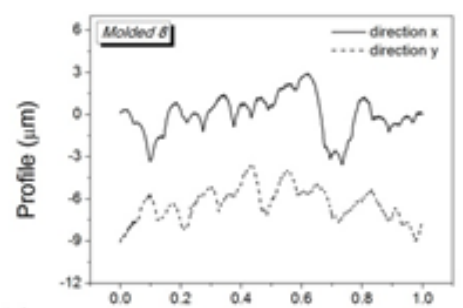

b)

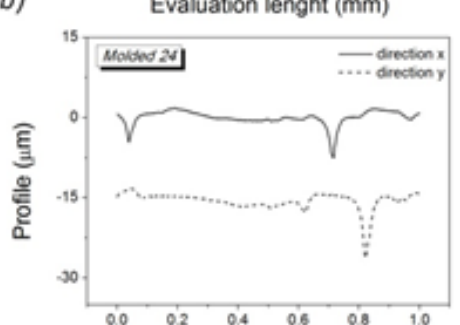

e)

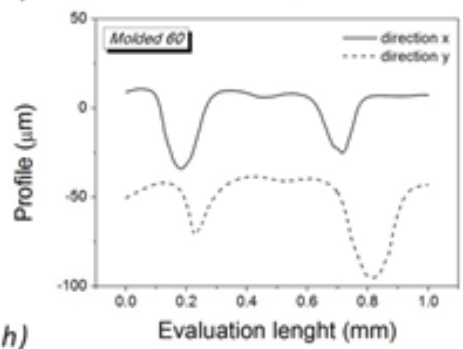

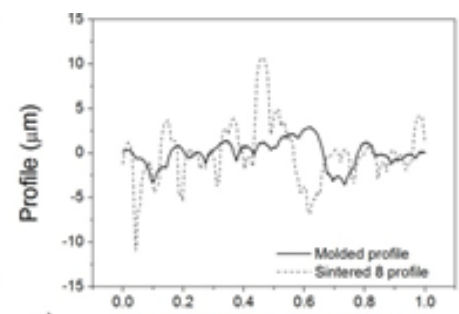

c)

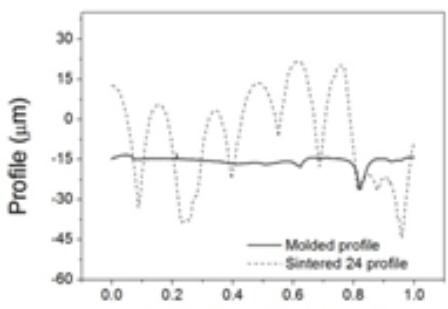

f)

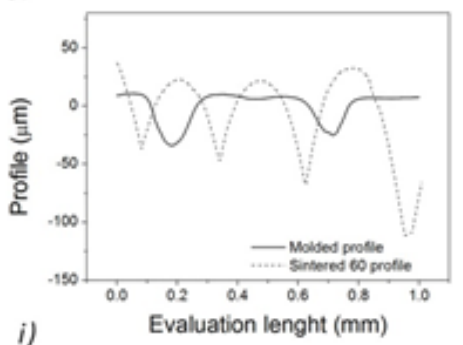

Fig. 4. 3D maps of the molded surfaces: Molded8 (a), Molded24 (d), Molded60 (g); two profiles in two different directions of the molded surfaces: Molded8 (b), Molded24 (e), Molded60 (h); comparison of the sintered mold profile and of the molded surface profile: Molded8 (c), Molded24 (f), Molded60 (i) 


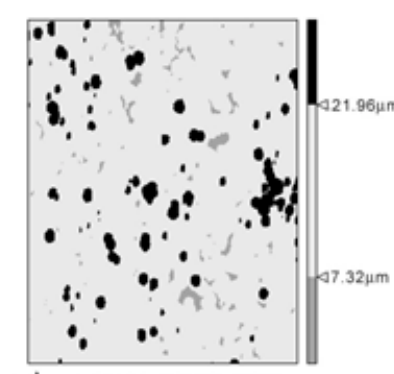

a) $\square 2.3 \% \square 90.6 \% \square 7.1 \%$

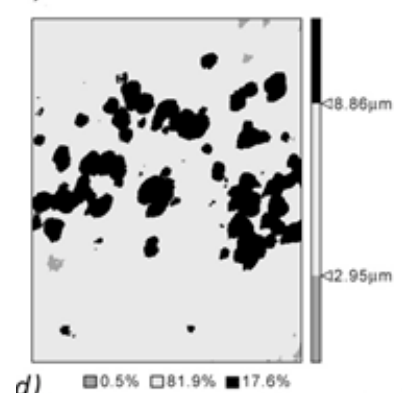

d) $\square 0.5 \% \square 81.9 \% \mathbf{m} 17.6 \%$

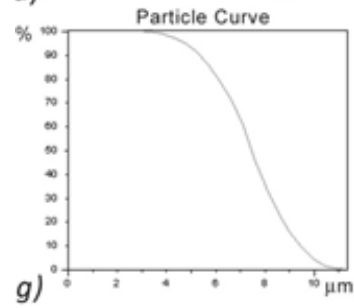

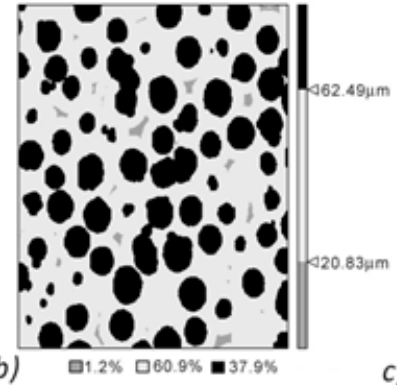
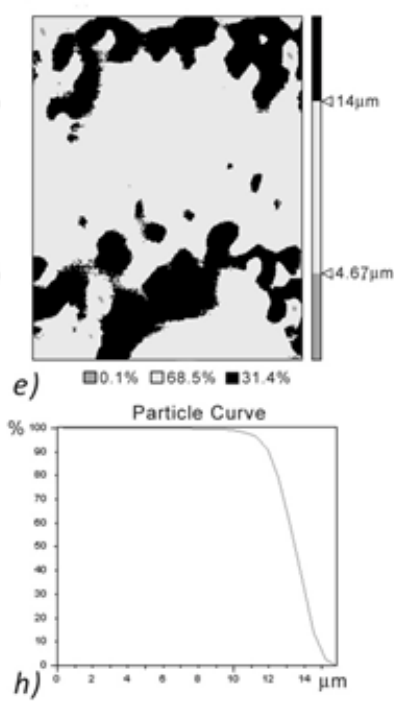
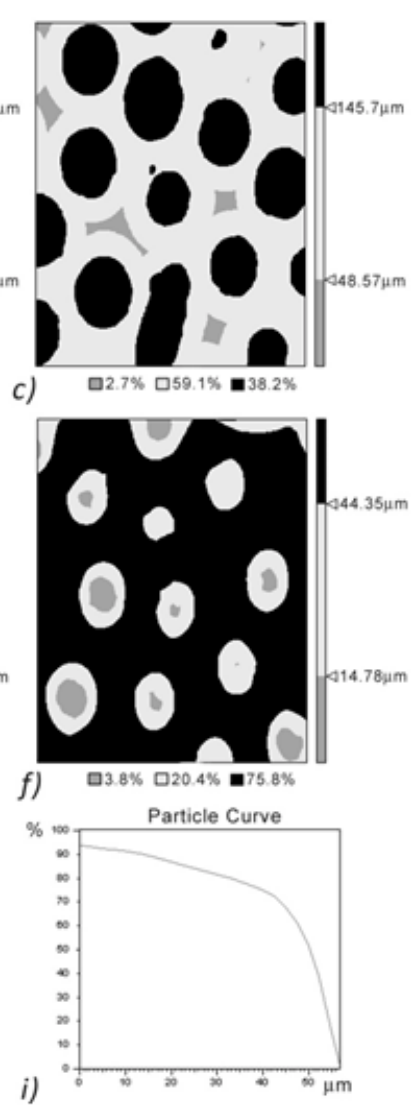

Fig. 5. Percentage distribution of the heights of the different areas of sintered molds: Sintered8 (a), Sintered24 (b), Sintered60 (c); percentage distribution of the heights of the different areas of molded surfaces particles curve distribution of the molded surfaces: Molded8 (d,g), Molded24 $(e, h)$, Molded60 (f,i) percentage distribution of the heights of the different areas of sintered molds. The variability of peak-valley spacing and distribution showed by mold surfaces also appears on the molded substrates. Thus, the three molded substrates are quite different from point to point, and no preferable orientation is evident. In particular, the Molded 8 and the Molded24 show flat zone and more localized waved zones, as if in some areas the surfaces are molded better than in others. This could be due to the initial waviness of the commercial Petri dish and to the surface-mold coupling. The phenomenon is less evident for the Molded60 due to the higher peak to valley values of the mold Sintered60.

In comparison to the no-textured Petri, the microtextured surfaces showed an increasing of the roughness parameters (table1). Moreover, Molded60 shows an high variability of roughness parameters along the two examined directions. The same behavior is also evident for Molded8 and Molded24.

The average roughness parameter Ra increases of an order of magnitude between no-textured Petri and Molded8 and Molded24, and increases of two order of magnitude between no-textured Petri and Molded60. The increment of the height of the roughness profiles, ranging from Molded8 to Molded60, is also underlined by $R_{t}$ values (total height of the roughness profile) (table1). The space parameter RSm (mean of the width of the profile curve elements) and the hybrid parameter RDq (root mean squared of the ordinate slopes $\mathrm{dz} / \mathrm{dx}$ ) underline an increase of spacing and slope of the profiles at the increase of the mold particles dimensions. The Rsk (degree of skew, symmetry of peaks and valleys using the average line as the center) shows negative values for all the textured samples, so as the surface is skewed upward relative to the average line. Moreover, the Rku (sharpness of a surface, pointing of the height distribution) values are close to 3 for Molded8, while are greater than 3 for Molded24 and Molded60, indicating that the height distribution of the molded surfaces is not sharp. These analysis underline that the polymeric material does not flow adequately into the mold valleys ( fig. $4 c, f, i$ ), on the other hand the mold peak are reproduced in detail. This occurs also because the pressure and the mold temperature values are not too much high. This choice was made to preserve the transparency of the Petri for the following microscopic evaluations of the cell adhesion and proliferation. Therefore, flat areas and depressions are evident on the molded surfaces, and the dimensions increase with the increasing of the sintered mold particle sizes, as expected (fig.5).

Figure 6 shows the of mouse embryonic fibroblasts (MEF) at $24 \mathrm{~h}$ and $48 \mathrm{~h}$ after seeding ( 250000 cells/p30) for the control sample and for the micropatterned surfaces. In the case of Molded8, the cavities are very small, comparable to the dimension of fibroblasts, about $15 \mu \mathrm{m}$, and do not uniformly distributed. After $24 \mathrm{~h}$ from seeding the cells adhesion appears good especially in the area among the cavities and where the density of the cavity is not too high. No cell is inside the cavity, probably for the small size of the cavities. After $48 \mathrm{~h}$ the presence of cells is higher in the area with less cavities. The nuclei have been counterstained with 4,6- diamidino-2-phenylindole (DAPI; $1: 1000)$ confirming that the cells are not found inside the cavities. For Molded24, the cavities are larger than for Molded8 and not evenly distributed. After $24 \mathrm{~h}$ there is a good cell adhesion, especially in the area among the cavities. After $48 \mathrm{~h}$ there is a cell proliferation in fact, the nuclear staining shows the presence of some cells in cavities.

For Molded60, the cavities are very large and depth, with irregular contours and internal roughness. The distribution is irregular too. After $24 \mathrm{~h}$ there is a good cell adhesion. After $48 \mathrm{~h}$ there is an increasing of the cells in the area among the cavities. The nuclear DAPI labelling shows the adhesion of the cells inside the cavities.

From these preliminary experiments, it is evident that the surface morphology influences the adhesion and proliferation of the cells. If the cavities have the same 

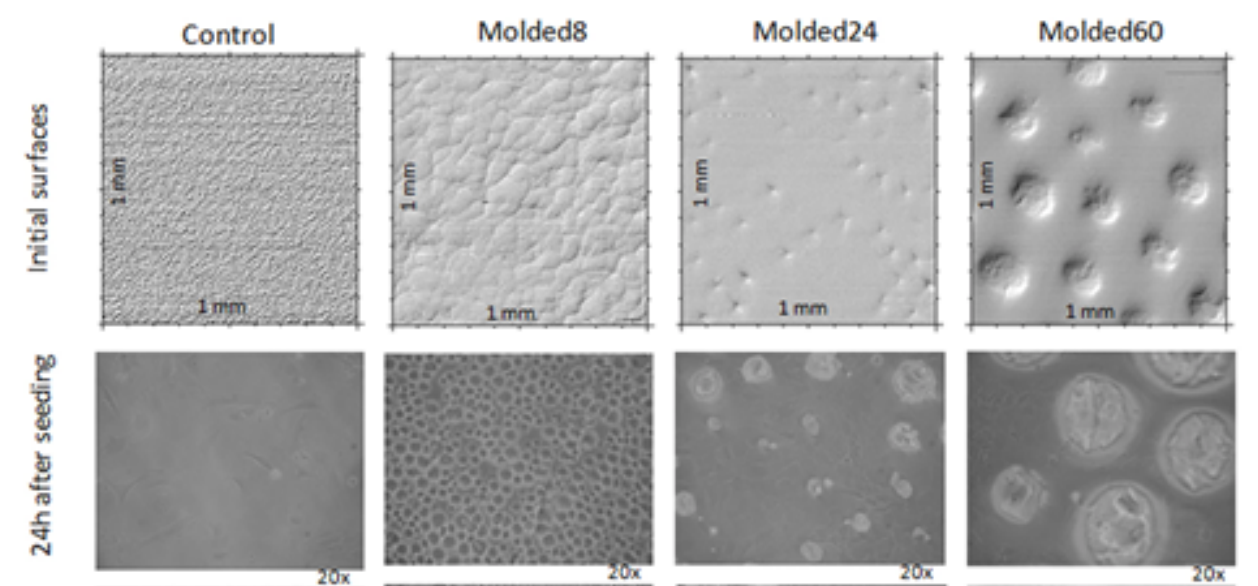

Fig. 6. MEF cell growth and proliferation at $24 \mathrm{~h}$ and $48 \mathrm{~h}$ after seeding for the control sample and for the micropatterned surfaces
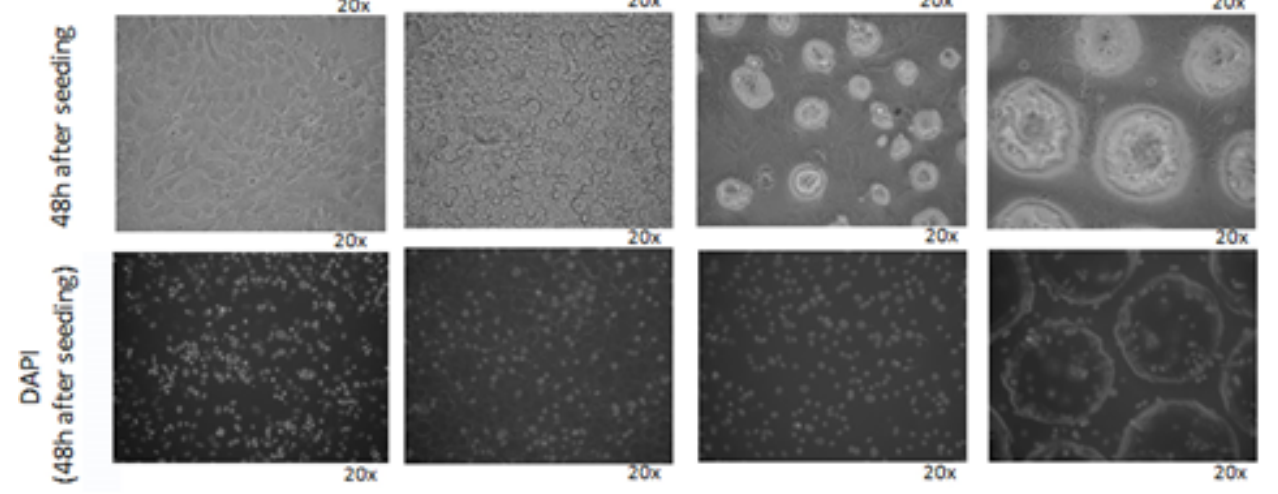

dimension of the cells no adhesion inside is possible, while higher and more rough cavities can promote the cell adhesion and proliferation.

\section{Conclusions}

In this paper, polystyrene (PS) Petri dishes were subjected to micropatterning by compression molding process using bronze sintered molds with different mean pore pitch sizes. An analysis of the surface changes was performed and the effect on adhesion and proliferation of cells of Mouse Embryonic Fibroblasts (MEF) P4 cells of the substrate was investigated. The micrometer surface modification did not significantly alter the adhesion and proliferation capacity of the MEFs cells, which essentially adapt to the cavities and surface roughness. Only in the case of cavities smaller than the cell size, the cells adhere to the edges of the cavities without penetrating. Moreover, the cells seems to prefer to adhere on flat and micro-rough areas. This work is the first step to prove as a simple, low cost and industrially scalable process for thermoplastic polymers could be applied for biomedical substrate devices for cell culture. The process could also be adapted to produce nano-sculptured or hierarchical surfaces, which can reproduce the microenvironment in which the cells reside in vivo. The work presents a suitable approach for mass production of micropatterned transparent thermoplastic surfaces at different length scales and provides a new way for designing surface structures with tailored properties.

\section{References}

1.LATTHE S.S., TERASHIMA C., NAKATA K., FUJ ISHIMA A., Molecules, 19, 2014, p. 4256.

2.WANG Y.L., et. al., Langmuir., 22, 2006, p. 8257.
3.TAO S.L., POPAT K.C., NORMAN J J ., DESAI T.A., Langmuir., 24, 2008, p. 2631.

4.XIA F., et. al., Adv. Mater., 18, 2006, p. 432.

5.SAARIKOSKI I., JOKI-KORPELA F., SUVANTO M., PAKKANEN T.T., PAKKANEN T.A., Surf. Sci., 606, 2012, p. 91.

6.RASILAINEN T., SUVANTO M., PAKKANEN T.A., Surf. Sci., 603, 2009, p. 2240;

7.HUOVINEN E., TAKKUNEN L., SUVANTO M., PAKKANEN T.A., J. Micromech., 24, 2014, 055017.

8.HUOVINEN E., HIRVI J., SUVANTO M., PAKKANEN T.A., Langmuir., 28, 2012, p. 14747.

9.GUAN W.S., HUANG H.X., CHEN A.F., J. Micromech., 25, 2015, 035001; 10.JANSON I.A., PUTNAM A.J., J Biomed. Mater. Res., 103, 2014, p. 1246;

11.DAVE P.C., DINGAL P., DISCHER D.E., Curr. Opin. Biotechnol., 28, 2014, p. 46;

12.SANJUKTA D., Biomaterials for Oral and Craniomaxillofacial Applications, 17, 2015, London;

13.*** Nuutinen T., Silvennoinen M., Päiväsaari K., Vahimaa P., Biomed. Microdevices., 2013, p. 279;

14.GRAUSOVA L., et. al., J. Nanosci. Nanotechnol., 9, 2009, p. 3524;

15.NIE L., et. al., Biochem. Eng. J., 98, 2015, p. 29;

16.CICUÉNDEZ M., et. al., J. Mater. Chem. B, 2, 2014, p. 49;

17.RICHTER C., et. al., Biomed. Microdevices., 12, 2010, p. 787 ;

18.LU H.W., et. al., Mater. Lett., 58, 2004, p. 29;

19.PRESTWICH G.D., J. Cell. Biochem., 101, nr. 6, 2007, p. 1370;

20.BEIGEL J., et al., Toxicol In. Vitro., 22, nr. 1, 2008, p. 171;

21. JOERGENSEN N.L. et. al., J. Biomed. Mater. Res. A., 104, nr. 12, 2016, p. 3073;

22.TEDDE M.G., BELLISARIO D., SANTO L., QUADRINI F., Key Eng. Mater., 699, 2016, p. 49.

$\overline{\text { Manuscript received: } 15.09 .2018}$ 